\title{
PERAN TRADISI DALAM TREND FORECASTING
}

\author{
Akbar Adhi Satrio, Tri Hasdianto, Amelinda Alysia A.V.K. \\ (akbaradhi.s@itb.ac.id) \\ Program Studi Kriya \\ Fakultas Seni Rupa dan Desain \\ Institut Teknologi Bandung \\ Jl. Ganesha No.10, Bandung, Indonesia
}

\begin{abstract}
ABSTRAK
Kajian ini merupakan analisis awal dari penelitian "Analisis Penerjemahan Trend Forecasting Dalam Konteks Kriya". Trend Forecasting atau prediksi tren merupakan salah satu metode yang dikembangkan untuk memprediksi tren di masa yang akan datang melalui riset berdasarkan analisis data faktual fenomena yang terjadi pada rentang waktu tertentu, mencakup perkembangan pola pikir, teknologi, gaya hidup, serta faktor-faktor lain pembentuk keputusan strategis dalam peracangan sebuah produk desain. Akan tetapi dalam konteks proses perancangan produk kriya di masa kini, peran prediksi tren perlu ditinjau kembali. Hal ini berkaitan dengan adanya unsur tradisi dalam produk kriya yang melekat pada produk dan perlu dipertahankan untuk menunjukkan karakter tradisi itu sendiri. Kajian ini berusaha untuk memetakan komponen-komponen dasar dalam metode prediksi tren serta posisi tradisi di dalamnya melalui: a) studi lapangan lembaga maupun praktisi di bidang prediksi tren; b) studi komparasi mengenai posisi tradisi dalam proses prediksi tren berdasarkan tiga literatur yaitu "The Trend Forecaster's Handbook", "How to Research Trend", dan "Fashion Forecasting". Hasil dari kajian ini menunjukkan bahwa peran tradisi dalam perspektif metode-metode prediksi tren yang dikaji memiliki peran signifikan sebagai salah satu data untuk membangun prediksi tersebut. Namun, perspektif tradisi dalam hal ini bukan dalam konteks budaya lokal namun lebih kepada kultur dan perilaku yang ada dalam lingkungan masyarakat.
\end{abstract}

Kata Kunci: kriya; tradisi; trend forecasting

\section{ABSTRACT}

This study is preliminary research of "The Trend Forecasting Translation Analysis in The Context of Craft". Trend Forecasting is a developed method that aims to predict future trends through research and analysis based on factual data of phenomena that occurs during certain time frames. The process includes analyzing various factors including technological development, lifestyle, also shifts of paradigm that form strategic decisions towards product design. However, the role of the trend forecast being applied to today's craft designing process needs to be further reviewed. It is related to the fact where traditional elements are attached to all craft products, emphasized to be well-preserved in showing its characteristics of culture and tradition. This study seeks to map where the position of tradition takes place among the trend forecasting process through the analysis of a.) field studies in institutions and practitioners in the field of trend forecast; b.) comparative study of the position of tradition in the process of trend forecasting based on three kinds of literature namely "The Trend Forecaster's Handbook", "How to Research Trends", and "Fashion Forecasting". In the scope of methods, the results of this study show that tradition stands as a significant data in the process of constructing a trend forecast. However, the perspective is not under the context of local culture but as the behavior of people.

Keywords: craft; tradition; trend forecasting 


\section{PENDAHULUAN}

Proses desain merupakan sebuah proses yang sangat dinamis dan melibatkan parameter yang sangat beragam dalam proses perancangannya, dan praktisi desain berperan sebagai agen perubahan pelaksana proses tersebut. Desain berperan untuk meningkatkan kualitas hidup penggunanya dengan merancang medium yang tidak terbatas hanya pada konteks inovasi sosial dan pengembangan fungsi maupun tampilan sebuah objek saja, namun juga dapat dilihat dari sisi filosofis bahwa objek desain merupakan sebuah katalis bagi penggunanya untuk dapat merespon suatu masalah dari sudut pandang yang berbeda (Caccavale \& Shakespeare, 2014). Salah satu perspektif dapat diambil dalam memetakan permasalahan desain adalah dengan melakukan prediksi terhadap fenomena yang akan terjadi di masa akan datang atau trend forecasting. Keterlibatan trend forecasting atau prediksi tren dalam proses desain pada umumnya adalah memberikan arahan terhadap apa yang akan menjadi populer di masa akan datang berdasarkan riset multi-disiplin untuk mendapatkan parameter-parameter terstruktur sehingga proses desain dapat lebih terarah dan fokus terhadap pasar yang akan berkembang (Evans, 2003).

Desain dalam konteks kriya memiliki peran tidak jauh berbeda dengan pengertian yang telah dipaparkan sebelumnya. Kriya tidak hanya bersandar pada nilai estetik, simbolik, dan filosofis semata, namun juga mempertimbangkan aspek fungsional, sifat material, teknik produksi, dan sumber energi untuk membuat objek tersebut (Gustami, 1992; Joedawinata, 2008). Hal ini menunjukkan bahwa walaupun selain terdapat parameter kualitatif, juga ada parameter kuantitatif sebagai bagian dari aspek yang perlu dipertimbangkan dalam merancang sebuah produk kriya. Produk kriya sebagai artifak tradisi dihasilkan dari kebudayaan, kebiasaan, dan pengetahuan yang diwariskan secara turun temurun kemudian membentuk nilai-nilai estetika maupun fungsi, tujuan fisik, dan ideologis, serta nilai ekonomi dan ekologi yang kuat terhadap produk kriya itu sendiri (Nugraha, 2010). Akibatnya, ada batasan tertentu untuk dapat dicapai dalam mengembangkan produk kriya terutama dalam memposisikan nilai tradisi yang harus dipertahankan agar identitasnya sebagai representasi budaya lokal tetap melekat.

Tulisan ini berusaha mengkaji permasalahan tersebut dan mengidentifikasi sejauh mana peran tradisi dalam metode-metode trend forecasting yang sudah ada. Pembahasan dalam tulisan ini dibatasi pada metode-metode trend forecasting yang pada literatur-literatur 
Serat Rupa Journal of Design, January 2020, Vol.4, No.1: 93-111

E-ISSN: 2477-586X, ISSN: 2338-3348 | https://doi.org/10.28932/srjd.v4i1.1959| Received: 05-10-2019, Accepted: 16-01-2020

Akbar Adhi Satrio, Tri Hasdianto, Amelinda Alysia A.V.K.

Peran Tradisi Dalanm Trend Forecasting

membahas tentang prediksi tren khususnya dalam bidang desain dan wawancara dilakukan terhadap narasumber yang dianggap memiliki kompetensi di bidang tersebut.

\section{METODE PENELITIAN}

Penelitian ini merupakan deskriptif kualitatif dengan mengambil sumber data berdasarkan wawancara dan analisis pustaka sebagai berikut:

1. Studi pustaka berdasarkan dua buku referensi yang secara umum membahas tentang metode-metode trend forecasting yaitu "The Trend Forecaster's Handbook (Second Edition)" dan "How to Research Trend"

2. Studi pustaka berdasarkan buku referensi yang secara khusus membahas tentang metode trend forecasting di bidang fesyen yaitu "Fashion Forecasting"

3. Wawancara tidak terstruktur dengan narasumber Tri Anugrah selaku Creative Director dari Indonesia Trend Forecasting

4. Wawancara tidak terstruktur dengan narasumber Adhitya Pattisahusiwa selaku Product Development Manager dari Apparel Transmarco Indonesia.

\section{TRADISI DAN TREND FORECASTING}

Istilah trend forecasting ini sering digunakan di berbagai bidang keilmuan lain seperti ekonomi, bisnis, maupun sains untuk menggambarkan pergerakan tertentu dalam sebuah kasus ataupun fenomena yang spesifik. Dalam konteks desain, berdasarkan kajian yang telah dilakukan dengan menelaah tiga literatur yaitu The Trend Forecaster's Handbook oleh Martin Raymond, How to Research Trend oleh Els Dragt, dan Fashion Forecasting oleh Evelyn L. Brannon dan Lorynn Divita, secara umum prediksi tren atau trend forecasting adalah salah satu metode yang dikembangkan untuk memprediksi tren di masa akan datang melalui riset berdasarkan analisis pergerakan atau perubahan pola pikir, teknologi, gaya hidup, serta faktor-faktor lain yang mempengaruhi perkembangan perspektif dalam kurun waktu tertentu (Brannon \& Divita, 2015; Dragt, 2018; Raymond, 2019). Dalam prosesnya, trend forecasting menggunakan beberapa metode untuk menyaring data dan informasi yang didapatkan untuk menghasilkan kesimpulan akhir mengenai tren yang akan muncul dalam rentang waktu tertentu di masa akan datang. Hasil daririset mengenai tren ini kemudian dirilis dalam sebuah laporan yang dapat digunakan oleh perusahaan sebagai acuan dalam pengambilan keputusan khususnya dalam proses pengembangan produk. 
Walaupun secara garis besar definisi trend forecasting berdasarkan tiga buku tersebut memiliki persamaan, namun berdasarkan kajian yang telah dilakukan terdapat perbedaanperbedaan khususnya metode-metode lapisan data dan sudut pandang masing-masing teori dalam memandang tradisi, budaya, atau kultur.

\section{Trend Forecasting Menurut Els Dragt}

Dalam buku How to Research Trend karya Els Dragt, tren didefinisikan sebagai pergerakan dan perubahan nilai-nilai dan kebutuhan di dalam masyarakat, kemudian terbentuk menjadi satu nilai yang termanifestasikan melalui berbagai macam cara di dalam berbagai kelompok masyarakat. Metode yang digunakan dalam buku ini membagi analisis tren menjadi tiga tahapan utama yaitu scan, apply, dan analyse (Dragt, 2018). Scan merupakan tahapan dengan indikasi-indikasi perubahan yang terjadi dideteksi berdasarkan penelusuran data-data mengenai fenomena telah dan sedang terjadi (spot) melalui riset lapangan, penelusuran media, serta mencari informasi melalui jejaring inovator maupun sesama trend spotter. Tahapan selanjutnya adalah menentukan dan menggali makna dari indikasi-indikasi yang memiliki pengaruh signifikan (select) untuk kemudian dilakukan penelusuran mendalam terkait indikasi tersebut agar dapat dideskripisikan secara lebih detail dan kemudian mengelolanya ke dalam bentuk arsip untuk mempermudah pengolahan di tahapan selanjutnya (document).

Setelah tahapan scan dilalui, selanjutnya data yang telah didapatkan akan masuk ke tahap analyse berupa data-data tersebut kemudian dibagi berdasarkan karakteristik dari masingmasing data menjadi kelompok-kelompok (cluster) untuk kemudian dianalisis melalui beberapa tahapan pertanyaan yang telah ditentukan sebagai indikator, sehingga karakteristik dari masing-masing kelompok dapat divalidasi urgensinya untuk dapat dipastikan menjadi sebuah kecenderungan tren (validate). Tahapan ini diakhiri dengan memberikan nama sebagai identitas bagi masing-masing kelompok tren (label).

Siklus proses analisis tren ini diakhiri dengan tahapan penerapan hasil analisis (apply). Proses ini mencakup identifikasi batasan dari masing-masing kategori tren dan menentukan cakupan tren yang dapat diaplikasikan oleh user atau client selaku pengguna hasil analisis tren (scope), menentukan metode untuk menyampaikan hasil analisis (communicate), dan terakhir membuat suatu penerjemahan hasil analisis agar dapat diadopsi oleh pengguna 
(translate). Dalam tahapan translate, seorang forecaster tidak hanya sekedar memaparkan penemuannya saja, namun diharapakan seorang forecaster dapat menjembatani antara nilai-nilai yang dimiliki oleh calon pengguna dengan ide kreatif. Dragt berpendapat bahwa nilai-nilai tren bukanlah variabel yang terisolasi namun diharapkan dapat berbaur dengan aspek lain, seperti nilai-nilai perusahan, nilai-nilai kelompok, dan lainnya (value meets value).
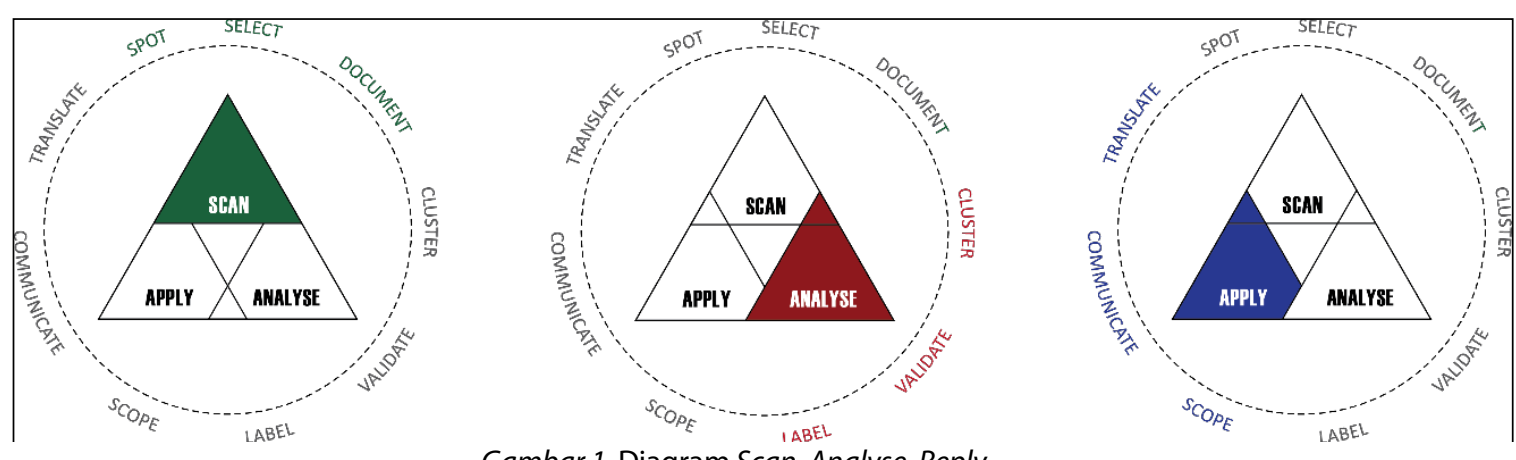

Gambar 1. Diagram Scan, Analyse, Reply

Secara khusus, Dragt tidak menyinggung mengenai tradisi atau budaya. Orientasi Dragt dalam bukunya lebih kepada penjelasan teknikal mengenai proses analisis dalam memprediksi tren dan bagaimana aplikasinya dalam membantu klien untuk mengembangkan produk atau usahanya.

\section{Trend Forecasting Menurut Martin Raymond}

The Trend Forecaster's Handbook yang ditulis oleh Martin Raymond memandang bahwa tren merupakan sebuah titik tuju pergerakan atau arahan sesuatu atau sekumpulan fenomena memiliki kecenderungan untuk mengarah kepada titik tersebut dan akibat dari pergerakan tersebut menghasilkan dampak kepada lingkungannya baik secara kultural, sosial, maupun bisnis (Raymond, 2019). Menurut Raymond, tren tidak sama dengan style. Style dapat didefinisikan sebagai suatu gaya yang mengacu pada estetika atau metode tertentu. Oleh karena itu, suatu style dapat dibedakan dengan style lainnya dengan melihat perbedaan masing-masing, mengacu pada parameter estetika tua metodenya masingmasing. Sedangkan tren tidak menekankan analisisnya pada perbedaan parameter estetik, akan tetapi lebih kepada analisis tahapan atau proses perubahan yang terjadi pada suatu fenomena.

Terdapat prinsip-prinsip dasar yang diterapkan oleh Raymond dalam bukunya dan prinsipprinsip inilah yang kemudian berkembang menjadi beberapa metode yang lebih rinci, namun dalam ranah konsep dasar menggunakan beberapa teori pendukung seperti teori dari Everett M. Rogers mengenai Diffusion of Innovation yang menjelaskan bahwa difusi dari 
Serat Rupa Journal of Design, January 2020, Vol.4, No.1: 93-111

E-ISSN: 2477-586X, ISSN: 2338-3348 | https://doi.org/10.28932/srjd.v4i1.1959| Received: 05-10-2019, Accepted: 16-01-2020

Akbar Adhi Satrio, Tri Hasdianto, Amelinda Alysia A.V.K.

Peran Tradisi Dalanm Trend Forecasting

sebuah inovasi memiliki pola yang cenderung sama terlepas dari apapun jenis inovasinya.

Pola tersebut umumnya dimulai dari tercetusnya ide sekelompok kecil orang yang digolongkan sebagai Innovator, kemudian secara bergiliran menularkan ide tersebut kepada kelompok yang lebih besar yaitu Early Adopters, yaitu kelompok yang dapat menerima bentukan ide yang masih berada di tahap paling awal. Setelahnya ide tersebut diteruskan kepada kelompok yang lebih besar lagi yaitu Early Majority, Late Majority, dan Laggards sebagai kelompok paling terakhir yang dapatmenerima ide atau inovasi baru.

Terkait dengan tradisi dan budaya, buku ini juga tidak membahas hal-hal tersebut secara mendetail akan tetapi terdapat beberapa pembahasan mengenai kultur sebagai salah satu parameter dalam metodenya. Pada bab kedua mengenai The Trend Forecaster's Toolkit, Raymond membahas mengenai cultural brailing dan cross-cultural analysis. Cultural brailing merupakan istilah yang diperkenalkan oleh Faith Popcorn dengan meminjam analogi dalam membaca sebuah kultur seperti meraba huruf braile untuk bisa mendapatkan interpretasi. Dalam melakukan cultural brailing, seorang forecaster harus mampu meraba segala perubahan dan hal-hal baru yang muncul, termasuk hal-hal yang bukan menjadi ketertarikan dirinya atau tanpa adanya informasi untuk mengetahui hal baru tersebut. Cultural brailing kemudian diaplikasikan pada tahapan lanjut dengan meraba indikasiindikasi perubahan serupa pada aspek atau bidang lain. Temuan kolektif ini kemudian dikaji untuk menghasilkan pengetahuan baru. Proses inilah yang disebut sebagai cross-cultural analysis. Untuk membantu, dalam tahapan cross-cultural analysis dikenal beberapa metode pendukung seperti memanfaatkan Wall of Evidence untuk menyusun data-data dalam bentuk visual yang dirangkai berdasarkan pola atau kategori tertentu, The Three-Times rule, menyusun analisis tekstual (Trend Thesis), diskusi dan wawancara mendalam (deep diving) dengan Expert Panel, bedah data untuk kemudian hasilnya dikaji berdasarkan sub-kelompok data yang lebih spesifik (Thin Slicing), dan Trend Cartogram.

\section{Trend Forecasting Menuru Evelyn L. Brannon dan LorynnDivita}

Buku Fashion Forecasting membahas secara spesifik fenomena dan metode forecasting dalam lingkup fashion yang lebih menekankan pada aspek pensuasanaan dalam rancangan, kecenderungan-kecenderungan dalam perilaku manusia, serta perilaku pasar terhadap daya beli. Konsumen menjadi perhatian utama dalam pencarian data terutama aspek-aspek yang berhubungan dengan kebutuhan (needs), keinginan (wants), dan apa yang diharapkan (aspiration) oleh konsumen (Brannon \& Divita, 2015). Brannon dan Divita juga berargumen bahwa dalam tren selalu terdapat sikulus yang terus berulang dan indikasi akan tren baru 
Serat Rupa Journal of Design, January 2020, Vol.4, No.1: 93-111

E-ISSN: 2477-586X, ISSN: 2338-3348 | https://doi.org/10.28932/srjd.v4i1.1959| Received: 05-10-2019, Accepted: 16-01-2020 Akbar Adhi Satrio, Tri Hasdianto, Amelinda Alysia A.V.K.

Peran Tradisi Dalanm Trend Forecasting

akan muncul pada dua belas hingga delapan belas bulan sebelum tren tersebut menjadi populer. Oleh karena itu, dalamfashion forecasting, pengelolaan waktu menjadi sangat penting.

Secara garis besar, fashion forecasting dibagi menjadi tujuh tahapan. Tahap pertama adalah tahap identifikasi tren terdahulu baik indikasi-indikasi yang muncul maupun siklus pada masa sebelumnya. Tahap kedua adalah identifikasi penyebab-penyebab perubahan yang terjadi pada tren sebelumnya untuk kemudian menjadi data bagi tahap ketiga yaitu studi komparasi dan analisis antara prediksi tren pada era sebelumnya dengan kondisi riil pada masa kini. Pada tahapan keempat, hasil analisis dari tahap ketiga diidentifikasi secara lebih detail untuk menghasilkan simpulan tentang faktor-faktor yang dapat menjadi posibilitas untuk memicu perubahan di masa datang.

Tahap kelima hingga ketujuh merupakan tahap aplikasi dan evaluasi. Pada tahap kelima seorang forecaster dituntut untuk melakukan analisis dengan menerapkan meteode-metode trend forecasting dengan tetap memperhatikan pergerakan isu kontemporer yang terjadi di dalam masyarakat secara paralel. Memasuki tahapan keenam, hasil dari prediksi tren dipantau secara berkala. Hal ini bertujuan untuk melihat apakah ada deviasi pada penerapannya dan mendeteksi adanya anomaly selama aplikasi tren berlangsung yang kemudian disimpulkan untuk menjadi bahan evaluasi dan revisi pada tahap ketujuh.

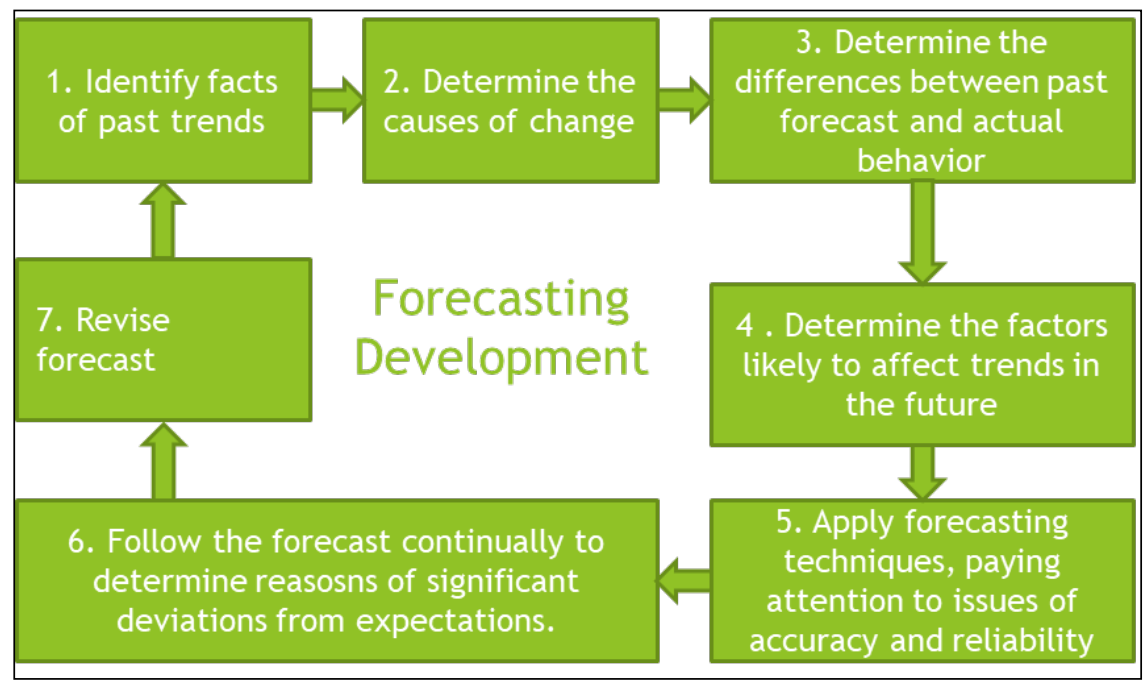

Gambar 2. Alur proses trend forecasting di bidang fashion menurut Evelyn L. Brannon dan LorynnDivita

Pembahasan mengenai tradisi tidak ditemukan secara khusus, akan tetapi terdapat pemaparan mengenai kultur. Kultur dipandang secara umum, bukan dilihat sebagai budaya 
Serat Rupa Journal of Design, January 2020, Vol.4, No.1: 93-111

E-ISSN: 2477-586X, ISSN: 2338-3348 | https://doi.org/10.28932/srjd.v4i1.1959| Received: 05-10-2019, Accepted: 16-01-2020

Akbar Adhi Satrio, Tri Hasdianto, Amelinda Alysia A.V.K.

Peran Tradisi Dalanm Trend Forecasting

atau tradisi secara spesifik. Dalam kasus sektor fashion, kultur dikaitkan erat dengan karya seni dan pembagiannya sebagai sumber inspirasi dan salah satu indicator penting. Karya seni diterjemahkan sebagai eksplorasi estetik yang memunculkan indikasi-indikasi visual yang baru (emerging aesthetic).

\section{TRADISI DALAM TREND FORECASTING DI INDONESIA}

Trend forecasting menjadi salah satu hal yang menjadi perhatian pemerintah Indonesia melalui Badan Ekonomi Kreatif (Bekraf) yang didirikan pada 20 Januari 2015, melalui Peraturan Presiden Republik Indonesia (Perpres) Nomor 6 Tahun 2015 Tentang Badan Ekonomi Kreatif, lembaga baru non kementerian yang bersama dengan lembaga-lembaga pemerintah maupun swasta terkait mengelola aktivitas ekonomi kreatif di Indonesia. Salah satu program yang dibuat adalah dengan membentuk Indonesia Trend Forecasting (ITF).

ITF memiliki berbagai macam entitas di dalamnya, yang bekerja untuk memprediksi tren. Sebagai tim riset kolaboratif, ITF memiliki peran untuk menelusuri dan menganalisis faktorfaktor penggerak tren, yang nantinya akan menjadi acuan dalam memprediksi tren di masa depan. Metode ITF dalam memprediksi tren ialah dengan mencari trend driver yang dapat member dampak pada perubaha tren. Seperti yang diutarakan oleh Tri Anugrah sebagai salah satu tim inti dari ITF, trend driver dapat dikatakan sebagai lapisan yang paling bawah sebelum melangkah ke tahap selanjutnya. Melalui pendekatan kreatif, trend driver kemudian diolah bersama-sama oleh anggota timsehingga menghasilkan empat tema. Keempat tema ini nantinya diolah oleh tim decoding agar dapat diaplikasikan ke dalam produk fashion, tekstil, desain produk, maupun desain interior. Menurut pandangan Anugrah, sektor kriya merupakan sektor yang penting karena bersentuhan dengan keseharian manusia. la berharap di kemudian hari sektor Kriya dapat menjadi sebuah object of desire (T. Anugrah, wawancara personal, 12 September 2019).

Adhitya Pattisahusiwa selaku Product Development Manager di salah satu brand internasional di Indonesia memberikan perspektif yang berbeda yaitu dari sudut pandang dunia bisnis. Salah satu ruang lingkup pekerjaan Pattisahusiwa adalah menyediakan tren bagi perusahaan tempatnya bernaung, hingga menjadi produk jadi yang siap dilepas ke pasar. Baginya, yang dibutuhkan oleh pelaku usaha ialah bagaimana cara mengurai tren, bukan untuk memprediksi tren. Berangkat dari pengalaman ini, ia menarik suatu kesimpulan bahwa apa yang dibutuhkan oleh klien ialah sesuatu yang relevan dengan pasar, sedangkan 
Serat Rupa Journal of Design, January 2020, Vol.4, No.1: 93-111

E-ISSN: 2477-586X, ISSN: 2338-3348 | https://doi.org/10.28932/srjd.v4i1.1959| Received: 05-10-2019, Accepted: 16-01-2020

Akbar Adhi Satrio, Tri Hasdianto, Amelinda Alysia A.V.K.

Peran Tradisi Dalanm Trend Forecasting

unsur tren merupakan salah satu variable pendukung untuk developing product. Disebabkan sifatnya yang berkaitan dengan pasar, sungguh berbahaya jika pelaku usaha menerapkan tren yang terbaru tanpa dipilah terlebih dahulu, terutama untuk pasar dalam negeri karena tipikal konsumen Indonesia bukanlah sebagai early adapter (A. Pattisahusiwa, wawancara personal, 12 September 2019).

Terdapat empat langkah dalam metode yang dilakukan oleh Adhitya dalam menentukan tren. Pertama, dengan melakukan cara konvensional yaitu dengan mengunjungi berbagai peragaan busana, melihat koleksi dari desainer, dan melihat brand-brand lain. Syaratnya ialah mengunjungi secara langsung agar seorang trend forecaster dapat merasakan ambiance yang ditampilkan. Kedua, melakukan market visit untuk melihat apa yang dijual saatini dibandingkan dengan enam bulan lalu. Ketiga yaitu mengunjungi pameran-pameran tekstil garmen untuk melihat teknologi garmen dan bahan yang sedang berkembang. Langkah terakhir ialah mengevaluasi penjualan mengenai faktor penerimaan konsumen terhadap koleksi yang telah dikeluarkan. Tidak lupa dengan memantau faktor lingkungan yang dapat membuat perubahan pada tren, seperti kondisi ekonomi, politik, global, yang patut direspon oleh seorang trend forecaster.

Kacamata di dunia industri retail terhadap faktor kriya dan tradisi dalam penentuan tren tidak terlalu signifikan. Faktor tradisi dalam dunia industri retail kebanyakan masih bersifat serapan, dan hanya mencoba relevan terhadap situasi di Indonesia saja, misalnya brand Uniqlo membuat produk dengan sentuhan motif batik terkesan hanya mencoba sesuatu yang baru saja. Perlu ditelaah kembali apa yang bisa menghubungkan tradisi dengan dunia luar, sebagai sebuah strategi, misalnya menghubungkan produk kriya tradisi dengan isu sustainable product dengan harapan konsumen membeli produk karena terdorong untuk berbuat sesuatu yang lebih baik bagi bumi. Tren di kriya tradisi saat ini masih bergelut di ranah komunitasnya sendiri, masih belum dapat bergerak lintas komunitas, dan terdapat mata rantai yang hilang sebagai penghubung unsur tradisi dengan dunia industri.

\section{PENUTUP}

Dari hasil kajian ini didapatkan dua kesimpulan. Pertama, dari hasil penjabaran mengenai metode-metode trend forecasting berdasarkan tiga literature terpilih, terdapat irisan dalam hal prinsip dasar dalam tahapan-tahapan analisis perkiraan tren yang dapat dirangkum menjadi lima tahapan utama yaitu: (1) melakukan identifikasi terhadap tren sebelumnya dan menentukan faktor-faktor yang memicu munculnya indikasi tren; (2) melakukan identifikasi 
Serat Rupa Journal of Design, January 2020, Vol.4, No.1: 93-111

E-ISSN: 2477-586X, ISSN: 2338-3348 | https://doi.org/10.28932/srjd.v4i1.1959| Received: 05-10-2019, Accepted: 16-01-2020 Akbar Adhi Satrio, Tri Hasdianto, Amelinda Alysia A.V.K.

Peran Tradisi Dalanm Trend Forecasting

terhadap prediksi yang telah dilakukan dengan kondisi aktual di masa prediksi itu muncul;

(3) perencanaan strategi prediksi dan menentukan metode yang akan digunakan untuk menganalisis indikasi dan data; (4) Memantau jalannya tren dan secara parallel mengelola tren yang sudah dihasilkan agar dapat terintegrasi dengan kebutuhan pengguna; (5) evaluasi dan revisi.

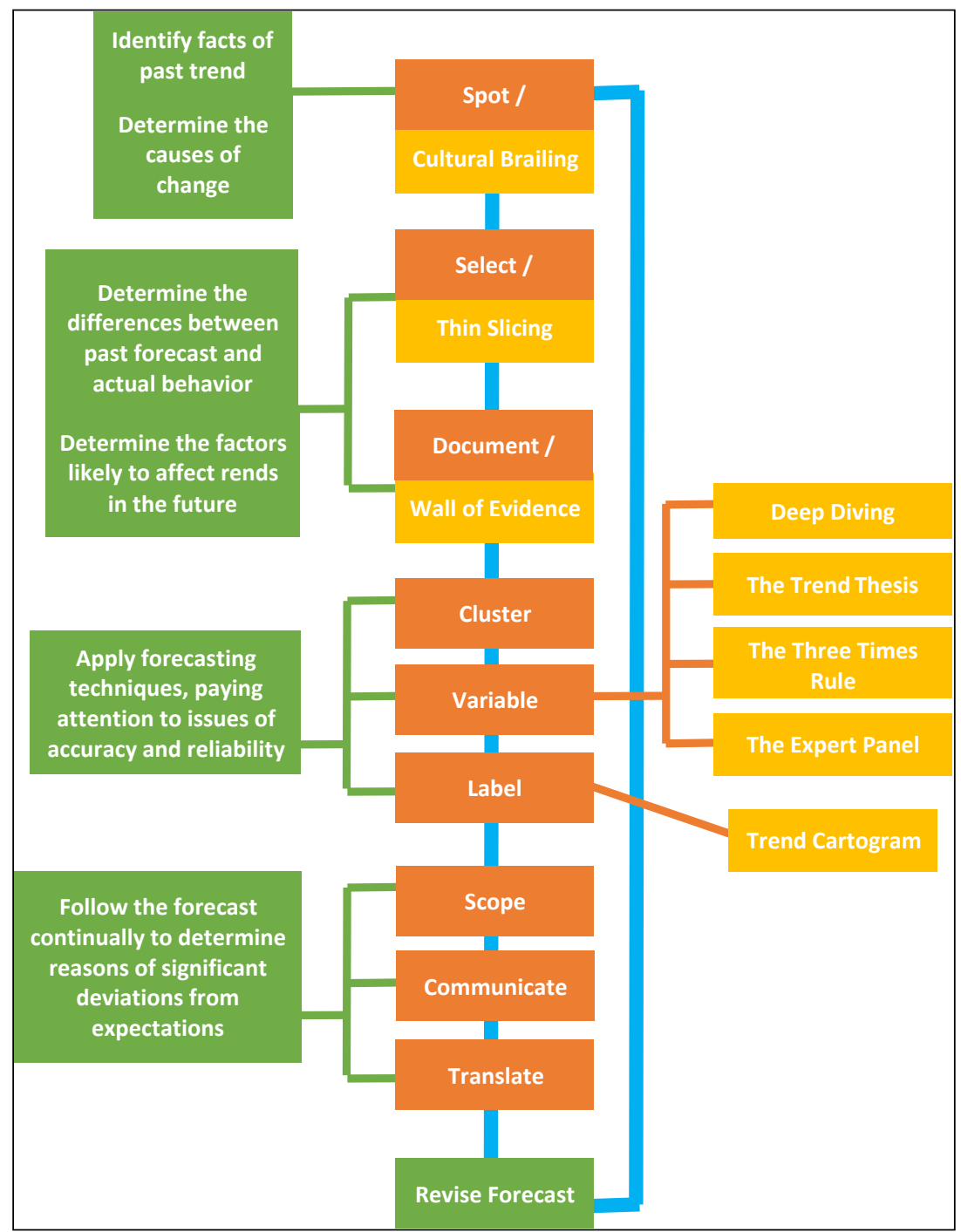

Gambar 3. Diagram analisis irisan tiga literature mengenai metode trend forecasting

Kedua, tradisi dalam perspektif metode-metode prediksi tren yang dikaji memiliki peran yang signifikan sebagai salah satu data untuk membangun prediksi tersebut. Namun, perspektif tradisi dalam hal ini bukan dalam konteks budaya lokal namun lebih kepada kultur dan perilaku yang ada dalam lingkungan masyarakat. Hal ini dikuatkan oleh pernyataan dari narasumber Tri Anugrah selaku perwakilan tim ITF dan Adhitya Pattisahusiwa yang menegaskan bahwa tradisi sebagai budaya lokal masih belum menjadi parameter utama. 
Serat Rupa Journal of Design, January 2020, Vol.4, No.1: 93-111

E-ISSN: 2477-586X, ISSN: 2338-3348 | https://doi.org/10.28932/srjd.v4i1.1959| Received: 05-10-2019, Accepted: 16-01-2020

Akbar Adhi Satrio, Tri Hasdianto, Amelinda Alysia A.V.K.

Peran Tradisi Dalanm Trend Forecasting

\section{DAFTAR PUSTAKA}

Brannon, E. L., \& Divita, L. (2015). Fashion Forecasting (Fourth Ed.). New York, London:

Bloomsbury Publishing Inc.

Caccavale, E., \& Shakespeare, T. (2014). Thinking Differently about Life: Design, Biomedicine, and "Negative Capability." In S. Yelavich \& B. Adams (Eds.), Design as Future-Making. https://doi.org/10.5040/9781474293907-0007

Dragt, E. (2018). How To Research Trends. Amsterdam: BIS Publishers.

Evans, M. (2003). Trend Forecasting for Design Futures. EAD Conf. 2003, 1-10.

Gustami, S. P. (1992). Filosofi Seni Kriya Tradisional Indonesia. SENI: Jurnal Pengetahuan Dan Penciptaan Seni, II(1), 71.

Joedawinata, A. (2008). Unsur-Unsur Pemandu dalam Artefak Tradisional: Artefak Peralatan Anyaman di Kawasan Cirebon. Jurnal Ilmu Desain, 3(2), 57-74.

Nugraha, A. (2010). Transforming tradition for sustainability through 'TCUSM' tool. Synnyt Origins: Finnish Studies in Art, 3, 20-36.

Raymond, M. (2019). The Trend Forecaster's Handbook (Second Ed.). London: Laurence King Publishing Ltd. 